\title{
Evolusi Saluran Interaksi di Era Internet
}

\author{
Benedictus Arnold Simangunsong \\ Program Studi Komunikasi, Universitas Pelita Harapan. \\ Sedang Menempuh Studi S-3 Bidang Komunikasi di Universitas Padjadjaran
}

\begin{abstract}
Abstrak
The development and advancement of technology affect how man interacts with others. The revolution of society interaction which was proposed by Straubhaar and LaRose, from pre-farming society to a farming society, into an industrial society, which was marked by the label of industrial revolution, to the nformation society, which is marked by the information revolution, shifted the way and man's attitudes both in terms of economy and interaction. In the information society, the revolution also takes place in message delivery, where face-to-face was common at first, to textual and visual delivery, which is a change in the internet era.
\end{abstract}

Key words: Interaction revolution, the way for interaction, internet, face-to-face, textual, visual

\section{PENDAHULUAN}

Kartun dari Peter Steiner dengan kata-kata, "On the internet, nobody knows you're a dog", menjadi suatu analogi yang menarik untuk menggambarkan bagaimana sifat anonimitas dari pengguna di internet. Individu akan sangat kesulitan untuk mengukur, menjelaskan bahkan mengetahui apakah presentasi diri di ruang virtual merupakan representasi diri sebenarnya di ruang riil. Analogi inilah yang dapat menggambarkan secara sederhana bagaimana cara maupun bentuk interaksi berbeda antara di ruang riil dengan ruang virtual.

Lebih dari 40 tahun sebelumnya, Marshall McLuhan dalam pernyataannya mengenai komputer di Journal of Economic History (1960) bahwa, “ penemuan dari sebuah medium baru seringkali menunjukkan karakteristik dan asumsi, seperti terjadi pada media sebelumnya", atau bisa dikatakan bahwa perkembangan media mengubah asumsi dan karakteristik dari penggunaan media.

Perbedaan cara interaksi juga dipengaruhi oleh cara hidup serta bentuk masyarakat yang membentuk budaya karena perkembangan teknologi sebagai suatu alat interaksi. Straubhaar dan La Rose (2011) secara baik menggambarkan perubahan teknologi sebagai suatu revolusi yang dialami masyarakat dalam kehidupannya karena perkembangan teknologi. Mulai dari masyarakat sebelum bertani yang ditandai oleh budaya berbicara atau tradisi oral (spoken words) di mana masyarakat pada masa ini berkelompok dan hidup dari berburu dan bercocok tanam. Namun pergeseran terjadi ketika ditemukan alat untuk mencari ikan (fishing), mengumpulkan kayu di hutan (logging), hingga penggalian bahan tambang (mining) merubah cara manusia berinteraksi. Tahap ini tradisi oral menjadi tradisi membaca. Tradisi membaca masih sangat terbatas hanya pada kalangan rohaniwan Katolik saja 
dan belum menjangkau masyarakat kebanyakan lainnya.

Munculnya revolusi industri merubah pula wajah tradisi membaca yang sebelumnya hanya terbatas menjadi ke lebih banyak orang yang bisa membaca ide atau pemikiran karena produksi massal dari penemuan mesin cetak. Kemudian pergeseran terjadi lagi ketika masyarakat mampu untuk konsumsi dan produksi pesan dengan melakukan adopsi terhadap teknologi digital. Tahap inilah yang menandakan perubahan besar dari cara manusia melakukan interaksi dengan manusia lainnya; karena teknologi digital telah menciptakan suatu media yang sangat interaktif yaitu internet.

Internet telah mengubah cara manusia melakukan interaksi sehari-hari dari lisan menjadi interaksi secara tertulis. Seperti dikatakan oleh Straubhaar \& La Rose (2000:14-15) bahwa era internet adalah era masyarakat informasi di mana individu lebih banyak menghabiskan waktu di belakang komputer dan mengubah bentuk media menjadi bentuk tertulis (computer-readable). Bentuk tertulis dalam media interaktif ini memungkinkan terjadinya pemahaman yang berbeda dengan kenyataan sesungguhnya. Salah satu fakta adalah munculnya suatu perubahan dalam sikap dan perilaku individu.

Perubahan sikap dan perilaku juga disoroti secara tajam oleh pengamat ketika struktur teknologi terjadi perubahan dari Web 1.0 menjadi web 2.0. Struktur dasar web 1.0 berfokus pada sifat komunikasi yang hanya berasal dari pemilik pesan tanpa adanya kesempatan bagi pengguna (penerima pesan) untuk berbagi isi dengan pemilik konten. Oleh karena itu pada struktur jenis ini, web 1.0 lebih bersifat membaca (read). Sedangkan pada struktur dasar web 2.0 lebih bersifat membaca dan menulis (read-write) karena itu pengguna bisa berbagi pengetahuan dan informasi secara online. Inilah yang disebut sebagai posisi sejajar dalam berkomunikasi.

Posisi sejajar dalam berkomunikasi dimaksudkan bahwa ada kesetaraan antara komunikator dan komunikan. Posisi setara ini menggambarkan bahwa hubungan antara individu yang berinteraksi mempunyai hubungan yang dapat dikatakan "sudah mengenal". Sehingga ketika ada kritikan, maka hal tersebut dapat ditanggulangi dengan lebih cepat atau komunikator dapat mengubah tulisan yang sudah ada. Inilah faktor hubungan (relationships) atau dapat dikatakan sebagai faktor bagaimana cara manusia berkomunikasi, bukan hanya isi (content) dari pesan itu sendiri.

Namun yang terjadi pada munculnya web 2.0, menjadikan individu dapat melakukan manipulasi terhadap presentasi diri yang dimunculkan. Manipulasi di media sosial, seperti Facebook yang merupakan salah satu contoh situs berbasis web 2.0, terjadi karena manusia mampu untuk memberikan presentasi dirinya tanpa diketahui peran dari diri sebenarnya. Namun media sosial ini merupakan sebuah media yang tidak hanya fokus pada sumber sebagai individu yang mempunyai motif untuk membuat pesan, namun fokus pula pada cara manusia melakukan interaksi yang seimbang. Interaksi yang seimbang atau sejajar ini merupakan bagian dari inovasi struktur 
dasar dari internet untuk menjawab kebutuhan dasar interaksi manusia.

Straubhaar \& La Rose (2011:15) menyatakan bahwa dalam masyarakat informasi alat yang sangat dominan untuk membantu individu untuk menciptakan, menyimpan, dan melakukan proses informasi adalah komputer. Komputer sebagai sebuah alat yang sangat dominan berkembang dan digunakan sebagai saluran untuk mengirimkan informasi dengan bantuan saluran lain, seperti telepon, internet provider, kabel optik, ataupun lainnya. Penggabungan inilah yang memunculkan sebuah nama baru yaitu New Media. New Media seperti internet, dengan kapasitas tidak hanya untuk membaca pesan, tapi juga bisa menyampaikan pesan kepada khalayak, bahkan bisa melakukan keduanya dalam waktu yang bersamaan. Kemampuan yang dimiliki oleh internet inilah menjadi faktor yang mendorong pergeseran cara manusia berkomunikasi. Pada awalnya manusia berkomunikasi dengan menggunakan tatap muka dengan pesan verbal, kemudian bergeser menjadi menggunakan sarana-sarana simbolik secara non-verbal seperti penggunakan tulisan dan gambar atau tekstual dan visual.

Era internet terutama dengan munculnya blog maupun media sosial merubah wajah dari bentuk komunikasi itu sendiri. Individu sebagai pengguna internet bukan hanya bisa mengkonsumsi pesan, tetapi juga memproduksi pesan itu sendiri dalan bentuk teks dan visual. Faktor tekstual dan visual menjadi sarana penting sebagai cara untuk berkomunikasi, karena 'new media' menggantikan hubungan manusia yang erat menjadi superfisial. Hubungan yang terjalin dalam tahap superfisial tidak membutuhkan tindakan yang terlihat langsung, tapi lebih melihat dari pesan, baik berupa teks maupun gambar, secara termediasi. Individu mempercayai bahwa apa yang ditampilkan merupakan kenyataan sebenarnya, walaupun belum tentu seperti yang sebenarnya.

\section{KOMUNIKASI NON VERBAL PADA RUANG VIRTUAL}

Saluran interaksi antar manusia secara sederhana bisa menggunakan dua jenis saluran yakni saluran verbal dan saluran non-verbal. Saluran verbal adalah sebuah saluran yang menekankan pada penggunana tanda-tanda yang berasal dari pembicaraan antar individu atau bisa dikatakan berasal dari isi suatu pembicaraan. Sedangkan saluran nonverbal secara riil lebih menekankan pada dua hal. Pertama adalah tanda-tanda visual, seperti ekspresi wajah, postur, jarak, gestur, serta lainnya. Kedua, adalah berkaitan dengan vokal atau tandatanda paralinguistik, seperti amplitudo, kualitas suara, tekana suara, serta lainnya. Sehingga dapat dikatakan bahwa pada ruang riil, individu ketika berinteraksi dengan individu lain bisa melihat, merasakan, serta mengetahui mengenai tanda-tanda yang dimunculkan dalam berinteraksi atau dengan kata lain umpan balik (feedback) dapat diketahui.

Ting Toomey (1999:115) memberikan gambaran bahwa komunikasi nonverbal adalah sebagai perilaku yang bukan bahasa (nonlinguistic) yang secara sadar atau tidak sadar di 'encode' dan 'decode' melalui berbagai macam saluran komunikasi. Konteks dari saluran 
komunikasi seperti yang dikatakan oleh Ting Toomey ini merujuk pada medium nonverbal sebagai ekspresi muka, gesture, dan lainnya. Pertanyaan yang akan kita coba dalami adalah ketika kita di ruang virtual, bagaimana kita mengetahui mengenai ekspresi wajah, gesture, postur dan lainnya?

Lalu bagaimana dengan bentuk tekstual pada internet menggantikan bentuk non-verbal pada ruang riil. Bentuk non-verbal adalah semua isyarat yang bukan kata-kata, atau dapat dikatakan bahwa komunikasi yang menggunakan bentuk non-verbal adalah rangsangan atau isyarat yang berada dalam suatu "setting" komunikasi. Seperti yang dikatakan oleh Erving Goffman bahwa komunikasi non-verbal identik dengan 'expression given off' yaitu komunikasi non-verbal yang terjadi ketika manusia berinteraksi satu dengan lainnya. Sehingga dapat dikatakan bahwa komunikasi secara nonverbal adalah terfokus bukan pada 'what is said' melainkan pada 'how is said' atau bagaimana cara individu berinteraksi. Dalam pemikiran Edward T. Hall dalam bukunya dinamakan sebagai 'bahasa diam (silent language)' dan 'dimensi tersembunyi (hidden dimension)', karena pesan-pesan nonverbal erat kaitannya dengan konteks atau situasi komunikasi.

Konteks pada media internet, maka tanda-tanda seperti suara, ekspresi wajah, ataupun jarak tidak lagi bisa digunakan. Pada konteks internet, tandatanda sosial lebih banyak menggunakan medium tekstual. Pengunaan simbol secara tekstual, juga belum tentu bisa menjawab persoalan perilaku dari pengguna karena sifat anonimitas dari pengguna tidak bisa kita ketahui, sehingga presentasi diri dari pengguna hanya bisa dijelaskan melalui dua saluran yang bersifat non-verbal, yakni teks dan visual. Karena itu dapat dikatakan bahwa pada interaksi yang termediasi, maka kata dan gambar merupakan representasi simbolik yang tidak secara aktual terlihat.

Reeves dan Naas

(2002:39) mengatakan bahwa sebagai representasi simbolik di mana "a person" diganti dengan sebuah gambaran mengenai seseorang (a picture of a person), dengan titik fokusnya adalah mengenai jarak di mana sebenarnya pada medium yang termediasi kondisi ini akan sangat sulit diketahui. Namun kita bisa saja mengikuti beberapa aturan seperti di bawah ini :

1. Aturan pertama, ketika khalayak melihat sebuah gambar mengenai seseorang yang muncul dengan fokus kedekatan, maka evaluasi mengenai orang dalam gambar tersebut akan semakin konsentrasi atau intensif

2. Aturan kedua, khalayak akan lebih perhatian pada suatu gambar seseorang apabila muncul dengan fokus

3. Aturan ketiga, gambar mengenai seseorang yang muncul dengan titik fokus yang dekat akan diingat lebih baik dibandingkan gambar yang fokusnya jauh.

Pertanyaannya kemudian bagaimana kita melakukan kalkulasi mengenai kedekatan atau tidak bila visual itu ada di ruang virtual yang juga dikatakan sebagai medium yang termediasi? Karena pemikiran Reeves dan Naas (2002) di atas penulis lihat sebagai bentuk mediasi pada 
media televisi dimana fungsi fokus pada seseorang bisa diatur secara dekat atau jauh. Pada ruang virtual, maka gambar atau foto seseorang yang ditempatkan di suatu situs atau blog atau media sosial tidak bisa dirubah secara tiba-tiba menjadi lebih dekat atau jauh fokusnya, namun sudah pasti seperti ketika ditempatkan di situs-situs tertentu. Oleh karena itu dapat dikatakan kedekatan atau tidak di ruang virtual ditentukan oleh kedekatan seseorang di ruang riil, interaksi yang dilakukan melalui sarana teks sehingga dapat kesan yang ditampilkan 'dianggap' sebagai kesan yang diterima dengan baik dan ditampilkan dengan interaksi yang intensif diantara keduanya.

Oleh karena itu penulis mengatakan bahwa gambaran seseorang di suatu media, khususnya internet, adalah gambaran dari seseorang yang berbeda, khas atau unik dari seseorang tersebut. Dengan keunikan tersebut khalayak akan 'merasa' serupa dengan pribadinya. Serupa dengan diri khalayak dapat di representasikan dengan ingatan akan pengalaman dirinya ketika berada pada kondisi yang serupa dengan foto yang ditampilkan dengan seseorang, sehingga khalayak atau teman interaksi di internet merasakan berada pada kondisi tersebut.

Kondisi lain yang perlu diketahui bahwa penempatan foto atau visual dalam medium internet bisa mengenali kondisi atau situasi orang tersebut (walaupun belum tentu kebenarannya), karena wajah seperti dikatakan oleh Mulyana (2004:201) adalah petunjuk untuk memahami emosi seseorang dimana emosional seseorang masih bisa dimanipulasi, dari pengaturan atau tampilan fisikal yang dimunculkan. Tampilan fisikal tersebut, misalnya pakaian yang dikenakan ketika foto diletakkan, latar belakang ketika foto diambil, pemakaian asesoris seperti terlihat dalam foto. Pengetahuan akan tampilan fisikal ini memudahkan seseorang untuk mengetahui karakteristik dan kesan yang ditampilkan oleh lawan bicara kita, tentu saja seperti sudah dikatakan sebelumnya bahwa faktor emosional kedekatan (pengalaman yang sama, keinginan untuk membuat foto yang serupa) menjadi faktor penentu terjadinya interaksi.

Lalu bagaimana dengan faktor tekstual dalam berinteraksi di ruang virtual ? Seperti dikatakan oleh Wallace (1999:28) mengenai internet dengan menganalogikan sebagai lingkungan tekstual (textual environment). Pernyataan Wallace dikatakan seperti di bawah ini :

"In text-based environment, you can't project your high status the way you could in visual mode; your commanding voice is silenced. Your contagious smile and raised eyebrow are invisible. Unless you bring your own graphical web sites and direct others to it, the main tool you have to manage the impression others forms about you is the QWERTY keyboard".

Pernyataaan dari Wallace di atas mengindikasikan bahwa setiap bentuk dan pengelolaan kesan yang kita lakukan sangat ditentukan oleh tulisan yang kita buat melalui "keyboard" komputer yang ada di hadapan kita.

Pemikiran lainnya dikemukakan 
oleh Susan J Ball bahwa komunikasi tatap muka dipertimbangkan sebagai 'the richest' medium, artinya ada kemampuan dari interaktan untuk menerima umpan balik secara langsung baik isyarat verbal maupun nonverbal artinya keberadaan sosial (social presence) dikategorikan tinggi. Sedangkan kalau difokuskan pada konteks di ruang virtual, maka keberadaan sosial interaktan dikatakan lebih impersonal dan tidak nyaman.

Dikatakan sebagai impersonal karena keberadaan sosial dari individu yang berinteraksi, baik karakteristik maupun atribut tidak bisa diketahui (anonim); sehingga individu ketika berkomunikasi hanya dibatasi oleh sedikit pengetahuan terhadap lawan bicara. Sedangkan dikatakan tidak nyaman karena batas-batas nilai maupun norma ketika berhubungan tidak digunakan lagi, misalnya mulai dari berkenalan hingga terus berhubungan. Sehingga dapat dikatakan bahwa di dalam ruang virtual faktor penentunya adalah kesan yang diciptakan oleh masing-masing orang sehingga selaras dengan pengalaman akan dirinya sendiri. Pengalaman tersebut bisa berupa latar belakang budaya, seperti kesamaan suku, kesamaan agama, kesamaan hobi, atau bentuk kesamaan lain.

Oleh karena itu dengan sarana tekstual, individu dihadapkan pada kenyataan mencoba mempersepsi maksud dari individu yang mengirim pesan sehingga kemungkinan untuk terjadinya kesalahan persepsi akan sangat besar, inilah yang disebut sebagai sifat impersonal. Karenanya untuk mengatasinya, seperti di media sosial, individu hanya berinteraksi dengan teman yang sudah ia kenal, bukan teman yang baru ia kenal. Namun, apabila teman interaksinya itu baru ia kenal, maka indikator kesan menjadi sangat penting. Kesan (impression) disini diartikan sebagai kesan yang bisa menarik perhatian, kesan yang sesuai dengan diri penerima, kesan yang membuka kembali ingatan khalayak akan situasi yang pernah ia alami sebelumnya.

Jadi sifat impersonal yang awalnya hanya pengambilan peran sosial, bisa berubah menjadi sifat interpersonal ketika pengelolaan kesan berhasil untuk menarik perhatian dari lawan bicara. Selain faktor tulisan yang sesuai dengan kesamaan, juga tata letak atau pengaturan di halaman profil diri dari pengguna menjadi perhatian sehingga penilaian terhadap khalayak sebagai teman interaksinya dapat diputuskan. Karena ketika kita berada di ruang virtual, maka persepsi menjadi sesuatu yang penting; dan persepsi itu berkaitan dengan seleksi, pengaturan, pemanggilan (recall) serta pengingatan (memorizing) terhadap suatu pesan.

Selaras dengan pernyataan yang dikemukakan oleh Markham (2004) dan Garcia, et.al (2009) bahwa ruang sosial pada saluran yang termediasi mencoba menggambarkan bagaimana Diri sendiri (self) dan Diri orang lain (other) dikonstruksi melalui sebuah interaksi. 
Karena itu pergeseran dari tempat (place) menjadi ruang (space) mengindikasikan bahwa kata-kata atau kalimat atau bahasa yang kita gunakan dalam teks serta data visual merupakan refleksi dan membentuk pemahaman kita mengenai dunia kita melalui proses dialogis.

Proses dialogis termediasi inilah, seperti dikatakan oleh Markham (2004:147), mengindikasikan adanya bentuk-bentuk budaya yang tergambarkan melalui pertukaran pesan dan kemudian hasil dari pertukaran pesan tersebut terjadi proses adopsi serta reproduksi dari kata, kalimat maupun bahasa secara tekstual tersebut. Bayangkan ketika kita berada di depan komputer, memasuki situs media sosial, dan kemudian mulai melakukan interaksi dengan orang lain. Pada saat kita akan merespon aksi orang lain dalam satu sistem jejaring kita, maka pada saat itulah kita berpikir dan mencoba untuk memilih kata, kalimat, bahasa bahkan foto yang tepat yang harus kita pikirkan; maka ketika kita melakukan pemilihan kata dan sebagainya itu dapat dikatakan bahwa secara sadar ataupun tidak kita membuka diri sebagai presentasi diri kita dengan cara memilih kata, kalimat, bahasa, bahkan foto berdasarkan pandangan kita terhadap dunia sekeliling kita.

\section{Simpulan}

Pergeseran penggunaan saluran verbal berbentuk bahasa menjadi nonverbal seperti teks dan visual menjadi sangat penting ketika kita berusaha untuk menjelaskan mengenai interaksi yang terjadi di ruang virtual. Ruang virtual dengan indikasi anonimitas dan ketidaknyamanan dalam norma menyebabkan faktor persepsi menjadi penting untuk dikaji. Sehingga dapat dikatakan persepsi terhadap sesuatu yang sifatnya nonverbal menjadi kesulitan tersendiri, seperti dikatakan oleh Edward T Hall, bahwa bentuk komunikasi nonverbal sangat tergantung dari konteksnya karena makna dari pesan yang dikirim bersifat tersembunyi dan diam.

Karena itu mencoba mengatasi dengan makin banyaknya individu yang menggunakan internet untuk berkomunikasi, misalnya di media sosial, maka dapat dikatakan faktor yang mendorong mereka berkomunikasi adalah pengelolaan kesan yang ditampilkan oleh pengguna. Pengelolaan kesan yang dilakukan oleh pengguna sangat tergantung dari kesamaan minat, seperti dikatakan oleh Ward (1999) seperti dikutip oleh Wiratama (2008:211) bahwa komunitas di dunia riil harus memiliki kesamaan lokasi fisik, maka lokasi fisik di dunia virtual disamakan dengan kesamaan minat, faktor lainnya adalah kesesuaian pengalaman, serta pengaturan letak ruangan, misalnya tampilan halaman, warna, profil, serta lainnya yang sesuai dengan ciri dan karakter dari lawan bicara. 


\section{Daftar Pustaka}

Ball, Susan. Online First Impression : Verbal, Vocal, Visual Factors on First Impressions. Missouri Western State College, USA.

Markham, Annette N. 2004. Representation in Online Ethnographies : A Matter of Context Sensitivity. Dalam buku Online Social Research : Methods, Issues and Ethics, Marks D Johns et.al, Peter Lang Publishing Inc, NY

Mulyana, Deddy. 2004. Komunikasi Efektif : Suatu Pendekatan Lintas Budaya. PT Remaja Rosdakarya, Bandung

Reeves, Byron \& Nass, Clifford. 2002. The Media Equation : How People Treat Computers, Television, and New Media Like Real People and Places. Cambridge University Press, USA.
Straubhaar, Joseph \& LaRose, Robert. 2000. Media Now : Communications Media in Information Age, $2^{\text {nd }}$ edition. Wadsworth Thomson Learning, USA

Straubhaar, Joseph \& LaRose, Robert, Lucinda Davenport. 2011. Media Now : Understanding Media, Culture and Technology, $7^{\text {th }}$ edition. Wadsworth Thomson Learning, USA

Toomey, Stella Ting. 1999. Communicating Across Cultures. The Guilford Press, New York

Wallace, Patricia M. 1999. The Psychology of the Internet. Cambridge University Press, USA 